\title{
Prevalence of and risk factors for intestinal parasite infections in pediatric patients admitted to public hospitals in Southern Brazil
}

\author{
Isis Almeida de Almeida ${ }^{[1]}$, Sabrina Jeske ${ }^{[1]}$, Marília Arndt Mesenburg ${ }^{[2]}$, \\ Maria Elisabeth Aires Berne ${ }^{[1]}$ and Marcos Marreiro Villela ${ }^{[1]}$
}

[1]. Programa de Pós-Graduação em Parasitologia, Instituto de Biologia, Universidade Federal de Pelotas, Capão do Leão, RS, Brasil.

[2]. Programa de Pós-Graduação em Epidemiologia, Centro de Pesquisas Epidemiológicas, Universidade Federal de Pelotas, Pelotas, RS, Brasil.

\begin{abstract}
Introduction: This study aimed to evaluate the prevalence of intestinal parasitosis and to identify risk factors associated therewith in hospitalized children. Methods: Three fecal samples from each patient were evaluated using three different techniques. The patients' nutritional and socioeconomic status and hematologic profiles were evaluated. Results: Of 106 children, $32.1 \%$ tested positive for intestinal parasitosis. The associated risk factors were low parental education levels and children's nail-biting habit. Eosinophilia, observed in 15 cases, was not associated with parasitosis. Conclusions: We recommend routine fecal parasitologic examination for hospitalized children and implementation of educational campaigns on the prevention of these diseases.
\end{abstract}

Keywords: Prevalence. Enteroparasitosis. Hospitalized children.

Children are at risk acquiring of parasitic infections, which have negative effects on their nutritional status and physical development. They are particularly susceptible to parasitic infection and reinfection because they are more exposed to pathogens, their immunity is not fully developed, and their personal hygiene efforts may not be satisfactory; they depend on the care of others ${ }^{1}$. Intestinal parasite infection may be asymptomatic or may present with clinical features such as abdominal pain, cramps, nausea, vomiting, diarrhea, anemia, weight loss, and lack of appetite ${ }^{2}$. Eosinophilia may occur secondary to parasitosis and is generally due to the intratissue biological cycle of some helminths. The more complex the cycle of the parasite in the host organism, the greater the eosinophilic rate. On the other hand, when parasitosis is limited to the digestive tract, eosinophilia is usually transient ${ }^{3}$.

Intestinal parasitosis is one of the most common causes of hospitalization in children, especially in the age group $0-5$ years; it is generally accompanied by symptoms such as diarrhea. However, because diarrhea is also a common symptom in viral and bacterial infections and parasitologic examination of the feces of hospitalized children is seldom performed, intestinal parasitic diseases are often underdiagnosed in these patients ${ }^{4}$. This study aimed to estimate the prevalence of intestinal

Corresponding author: MSc. Sabrina Jeske.

e-mail: sabrinajeske@hotmail.com

Received 22 March 2017

Accepted 24 August 2017 parasitosis in children admitted to the pediatric units of public hospitals in the City of Pelotas, Southern Brazil, and to identify associations between parasitosis and eosinophilia, nutritional status, and socioeconomic factors.

An epidemiologic prevalence study was conducted over a one-year period. The target population was children aged 6 months to 11 years who were hospitalized in the public pediatric units of the two largest hospitals in the City of Pelotas, Rio Grande do Sul (RS), Brazil, which hosts the $3^{\text {rd }}$ Regional Health Coordination of RS and includes 22 municipalities in Southern RS. It has an estimated population of 845,135 inhabitants.

Participation in the study was voluntary. First, parents or guardians who were willing to have their children participate in the study signed an informed consent agreement; they were then invited to answer a semi-structured questionnaire to establish the patients' socioeconomic profiles and to identify other epidemiologic characteristics. The following variables were evaluated: age; sex; place of residence; family income; parental level of education; presence of domestic animals in the household; availability of sewage facilities, garbage collection services, and drinking water; occurrence of symptoms suggestive of intestinal parasitosis; nail-biting; walking barefoot; and knowledge of common worms and protozoa.

After completing the questionnaire, three preservative-free collection bottles pre-identified with the number/name of each child and responsible adult were distributed, together with instructions on how to collect the required fecal samples. The collected fecal material was taken to the Human Parasitology 
Laboratory of the Federal University of Pelotas and processed using Ritchie and Faust techniques and the Baermann-Moraes method. All research participants whose results were positive were given medical prescriptions and free treatment. The research was approved by the University Ethics Committee under number 177/2011.

Eosinophilia was determined from the differential count of the complete blood count; these results were obtained from the hospital's clinical analysis laboratories, with due authorization given by responsible adults and institutions. The relationship between the number of eosinophils and intestinal parasite presence/ absence and species was determined. Each child's nutritional status was determined by anthropometric evaluation of weight and height measurements. Anthropometric data were stored in a Microsoft Excel ${ }^{\circledR}$ spreadsheet and were analyzed using World Health Organization (WHO) Anthro version 3.2.2 software (Software for assessing growth and development of the world's children. Geneva: WHO, 2010, http://www. who.int/childgrowth/software/en/). For children older than 5 years, the body mass index was calculated and the values obtained were assessed according to charts recommended by the WHO.

Children were divided into two groups: Those with intestinal parasite infection (positive group) and those without (negative group). Descriptive comparisons between the two groups were performed using frequency and percentages. Statistical associations between infection status and patients' socioeconomic characteristics and habits were evaluated using Poisson regression, considering a level of significance of 5\%. The analysis was performed using Stata statistical software, release 13.0 (StataCorp LP, College Station, Texas, USA).

A total of 106 fecal samples were collected and analyzed. Of these, $34(32.1 \%)$ tested positive for at least one parasite species or intestinal commensal organism (Table 1), the most relevant of which were Trichuris trichiura (38.2\%), Ascaris lumbricoides and Endolimax nana (both 35.3\%), Giardia lamblia (14.7\%), and Entamoeba coli (11.8\%). The majority of the cases were monoparasitic (70.6\%). A higher proportion of positive cases was observed in children aged 6-11 years $(p=0.05)$ and in families with a lower monthly income $(p=0.06)$. The association with income, although not statistically significant, is presented and the variable retained in the multivariable model because of its importance as a determinant of infectious diseases. Table 2 shows a statistically significant crude association between intestinal parasite positivity and low parental/guardian education level $(p=0.03)$; children whose parents/ guardians studied for no more than 8 years had a 2.4 times greater chance of having intestinal parasites than those whose parents had completed 9 years of education or more. Children who bit their nails were 2.5 times more likely to have parasitic infections than those who did not $(p=0.01)$. No other variables were significantly associated with intestinal parasitosis. In the adjusted analysis, no significant associations were identified, probably due to the limited sample size. It is important to consider that the more variables included in the model the greater the number of stratifications; this widens confidence intervals and decreases statistical power. However, it is important to note that the adjusted prevalence ratios remained similar to the crude estimates.

In terms of nutritional status (Table 3), 68.9\% of the children analyzed were classified as being adequately nourished and only $0.9 \%$ were malnourished. Among children whose fecal samples were parasite positive, $61.8 \%$ were adequately nourished; none were malnourished. Therefore, there was no relationship between nutritional status and intestinal parasitosis. Eightyseven (of the 106 included children) underwent hematologic testing; eosinophilia was observed in 15 (17.3\%), three of whom

TABLE 1: Type of parasitism and species of intestinal parasites and/or commensals detected in hospitalized children in Pelotas, Rio Grande do Sul State, Brazil.

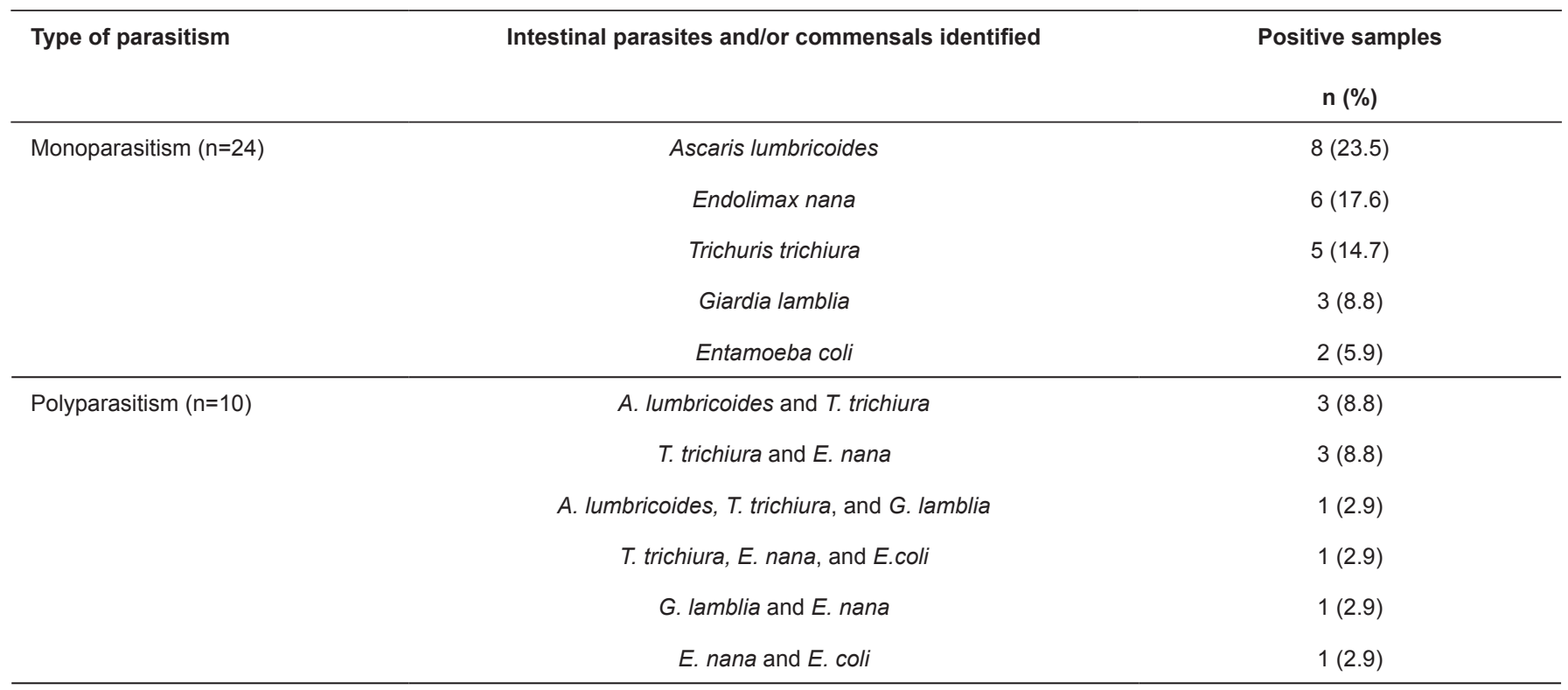


TABLE 2: Factors associated with intestinal and/or commensal parasitosis in hospitalized children in Pelotas, Rio Grande do Sul State, Brazil.

\begin{tabular}{|c|c|c|c|c|c|c|c|}
\hline Variable & Category & Total $(n=106)$ & $\begin{array}{l}\text { Positive cases } \\
(n=34), n(\%)\end{array}$ & $\begin{array}{l}\text { Crude PR coefficient } \\
\qquad(95 \% \mathrm{Cl})\end{array}$ & $p$-value & $\begin{array}{l}\text { Adjusted PR coefficient } \\
\qquad(95 \% \mathrm{Cl})^{*}\end{array}$ & $p$-value \\
\hline \multirow[t]{2}{*}{ Age } & $0-5$ years & 80 & $21(26.3)$ & ref & 0.05 & ref & 0.27 \\
\hline & $6-11$ years & 26 & $13(50.0)$ & $2.1(1.03-4.12)$ & & $1.52(0.72-3.24)$ & \\
\hline $\begin{array}{l}\text { Family } \\
\text { income }\end{array}$ & $\leq 1$ minimum wage & 55 & $23(41.8)$ & $1.94(0.95-3.98)$ & 0.06 & $1.54(0.72-3.29)$ & 0.27 \\
\hline \multirow{2}{*}{$\begin{array}{l}\text { Parents' } \\
\text { education }\end{array}$} & $\leq 8$ years & 70 & $28(40.0)$ & $2.40(1.00-5.79)$ & 0.03 & $1.91(0.76-4.83)$ & 0.17 \\
\hline & $\geq 9$ years & 36 & $6(16.7)$ & ref & & ref & \\
\hline
\end{tabular}

PR: Poisson regression; 95\% Cl: 95\% confidence interval; ref: reference category. *Adjusted by age, family income, parent's education and nail-biting habit.

TABLE 3: Nutritional status and eosinophilia related to enteroparasite positivity in hospitalized children in Pelotas, Rio Grande do Sul State, Brazil.

\begin{tabular}{|c|c|c|c|c|}
\hline & & Positive (\%) & Negative (\%) & Total (\%) \\
\hline \multirow{3}{*}{ Nutritional status } & Malnourished & $0(0.0)$ & $1(2.9)$ & $1(0.9)$ \\
\hline & Slimness & $1(2.9)$ & $3(8.8)$ & $4(3.8)$ \\
\hline & Overweight risk & $9(26.5)$ & $9(26.5)$ & $18(17)$ \\
\hline \multirow[t]{2}{*}{ Eosinophilia } & Present & $3(17.6)$ & $12(17.1)$ & $15(17.2)$ \\
\hline & Absent & $14(82.4)$ & $58(82.9)$ & $72(82.8)$ \\
\hline
\end{tabular}

had intestinal parasites detected in their fecal samples - the identified parasites were commensal protozoans (Endolimax nana and Entamoeba coli). No association was observed between eosinophilia (defined as an increase of $\geq 5 \%$ in the number of eosinophils) and parasitosis $(p=0.51)$.

Although intestinal parasites are known to represent a relevant public health hazard and may be indicators of socioeconomic development in specific areas, current information on such infections is limited, especially in terms of hospitalized children ${ }^{5}$. The prevalence of intestinal parasitosis in this study was $32.1 \%$, which is similar to the findings from other studies of hospitalized children, with reported prevalence rates of $32.1 \%^{6}$ and $38.5 \%{ }^{7}$. Although the prevalence in this study is similar to those reported in studies of schoolchildren, one cannot ignore the fact that hospitalized children are generally more immunologically fragile, i.e. are more susceptible to other infections or to a worsening of parasitosis ${ }^{6}$. The higher frequency of positive cases among those aged 6-11 years reinforces the idea that these children are more at risk of intestinal parasitosis due to the immature immune system; inadequate personal hygiene habits; greater contact with the soil, street, other children, and domestic animals; and are exposed to greater transmission risks, for example, among classmates ${ }^{1,4}$.

In terms of intestinal parasites detected, the most common helminths found in this study were Trichuris trichiura and Ascaris lumbricoides, both of which transmitted via the fecaloral route and have similar risk factors, especially in areas with precarious socioeconomic conditions ${ }^{8}$. Environmental contamination by these parasites has been detected in the City of Pelotas, both in student environments ${ }^{9}$ and in the public square ${ }^{10}$. Therefore, children may be exposed to environments that favor parasitic infection as the eggs of these nematodes are common environmental contaminants and present high resistance under different climatic conditions.

Low family income level (up to 1 minimum wage) was not significantly associated with intestinal parasitosis in the present 
study, but is considered a risk factor in studies in other developing countries, such as Malaysia, where low household purchasing power is thought to influence intestinal parasitosis via reduced access to health care, sanitation, and health-related information ${ }^{11}$. Parental level of education was significantly associated with intestinal parasitosis, with an inverse relationship demonstrated. Other studies have highlighted lack of formal schooling of parents as an important risk factor, demonstrating a decreasing frequency of parasitosis with increasing levels of parental education ${ }^{12}$; individuals with higher levels of education can positively affect the health of their family members. Regarding behavior and hygiene habits, nail-biting was shown to be a risk factor for parasitic infection acquisition; this is consistent with the findings from other studies. Nail-biting facilitates parasite contamination when proper nail and hand hygiene is not observed ${ }^{5}$.

In contrast to other studies that have demonstrated a relationship between eosinophilia and the presence of helminths ${ }^{3}$ and protozoa ${ }^{13}$, no such association was observed in this research. This may be related to factors influencing eosinophilia, such as parasite species, location, and load; host responses; duration of infection; and stage of parasite development ${ }^{14}$. Analysis of the children's anthropometric data in this study revealed that most were adequately nourished and that obesity prevailed over malnutrition. No relationship was observed between malnutrition and the presence of intestinal parasitosis. This may be related to an increase in obesity in all population strata, especially in families with lower purchasing power, since the type of diet ingested is usually high in $\mathrm{fat}^{15}$.

The overall percentage of children with intestinal parasitosis in this study demonstrates that parasitic diseases are common in this area, affecting more than a third of children hospitalized in public pediatric wards. It has been shown that low parental education level and children's nail-biting habits contribute to the prevalence of intestinal parasitosis. Therefore, educational campaigns on the prevention of these diseases should be implemented at health centers and hospitals. In addition, given the ease of performing the examination in a hospital environment, it is suggested that parasitologic examination of fecal samples should be routinely performed in pediatric units of hospitals, as a precise diagnosis is associated with health promotion. Education will certainly help to decrease the prevalence of these infections.

\section{Conflicts of interest}

The authors declare that there is no conflict of interest.

\section{REFERENCES}

1. Krause RJ, Koski KG, Pons E, Sandoval N, Sinisterra O, Scott ME. Ascaris and hookworm transmission in preschool children from rural Panama: role of yard environment, soil eggs/larvae and hygiene and play behaviours. Parasitology. 2015;142(12):1543-54.

2. Mariath AB, Giachini RM, Lauda LG, Grillo LP. Estado de ferro e retinol sérico entre crianças e adolescentes atendidos por equipe da Estratégia de Saúde da Família de Itajaí, Santa Catarina. Ciênc. Saúde Coletiva. 2010;15(2):509-16.

3. Silva CCV, Ferraz RRN, Fornari JV, Barnabé AS. Epidemiological analysis of eosinophilia and elevation of immunoglobulin $\mathrm{E}$ as a predictable and relative risk of enteroparasitosis. Rev Cubana Med Trop. 2012;64(1):22-6.

4. Núñez Fernández FA, Hernández Pérez SM, Ayllón Valdés LL, Alonso Martín MT. Hallazgos epidemiológicos en infecciones parasitarias intestinales de un grupo de niños ingresados por diarreas. Rev Cubana Med Trop. 2013;65(1):26-35.

5. Cañete R, Díaz MM, Avalos García R, Laúd Martinez PM, Manuel Ponce F. Intestinal parasites in children from a Day Care Centre in Matanzas City, Cuba. PLoS One. 2012;7(12):e51394.

6. Ferreira H, Lala ERP, Czaikoski PG, Buschini MLT, Monteiro MC. Enteroparasitoses e déficit nutricional em crianças hospitalizadas, Guarapuava, Estado do Paraná, Brasil. Acta Sci Health Sci. 2006;28(2):113-7.

7. Devera R, Blanco Y, Amaya I, Requena I, Rodríguez Y. Coccidios intestinales en niños menores de 5 años con diarrea. Emergencia pediátrica, Hospital Universitario Ruiz y Páez. Rev Soc Ven Microbiol. 2010;30(2):140-4.

8. Silva JC, Furtado LFV, Ferro TC, Bezerra KC, Borges EP, Melo ACFL. Parasitismo por Ascaris lumbricoides e seus aspectos epidemiológicos em crianças do Estado do Maranhão. Rev Soc Bras Med Trop. 2011;44(1):100-2.

9. Gallina T, Silva MAMP, Castro LLD, Wendt EW, Villela MM, Berne MEA. Presence of eggs of Toxocara spp. and hookworms in a student environment in Rio Grande do Sul, Brazil. Rev Bras Parasitol Vet. 2011;20(2):41-2.

10. Moura MQ, Jeske S, Gallina T, Vieira JN, Berne MEA, Villela MM. Frequency of geohelminths in public squares in Pelotas, RS, Brazil. Rev Bras Parasitol Vet. 2013;22(1):175-8.

11. Ngui R, Saidon I, Chow SC, Rohela M, Lim YAL. Prevalence and risk factors of intestinal parasitism in rural and remote West Malaysia. PloS Negl Trop Dis. 2011;5(3):e974.

12. Yentur DN, Gurses G, Simsek Z, Yildiz ZF. Prevalence and associated risk factors of intestinal parasites among children of farm workers in the southeastern Anatolian region of Turkey. Ann Agric Environ Med. 2015;22(3):438-42.

13. Cotton JA, Amat CB, Buret, AG. Disruptions of Host Immunity and Inflammation by Giardia duodenalis: Potential Consequences for Co-Infections in the Gastro-Intestinal Tract. Pathogens. 2015;4(4):764-92.

14. Bradley JE, Jackson JA. Immunity, immunoregulation and the ecology of trichuriasis and ascariasis. Parasite Immunol. 2004;26(11-12):429-41.

15. Batista Filho M, Rissin A. A transição nutricional no Brasil: tendências regionais e temporais. Cad Saude Publica. 2003;19(1): 181-91. 